\title{
PSA y hK2 en el diagnóstico de cáncer de próstata
}

\author{
Alapont Alacreu JM, Navarro Rosales S*, Budía Alba A, España Furió F*, Morera Martínez F, \\ Jiménez Cruz JF.
}

Servicio de Urología $y{ }^{*}$ Centro de Investigación. Hospital Universitario La Fe. Valencia.

Actas Urol Esp. 2008;32(6):575-588

\section{RESUMEN}

PSA Y hK2 EN EL DIAGNÓSTICO DE CÁNCER DE PRÓSTATA

Los marcadores séricos de cáncer de próstata son ampliamente usados para la detección precoz de este cáncer, estadiaje tumoral y para la monitorización tras tratamiento curativo o paliativo. Desde su descubrimiento en 1979, el PSA ha sido el marcador de cáncer de próstata más importante. Sin embargo, el PSA de forma aislada no presenta una especificidad y sensibilidad adecuadas como para considerarlo un test idóneo en la detección precoz de cáncer de próstata. Para aumentar la especificidad se han desarrollado los conceptos de velocidad de PSA, PSA-edad, densidad de PSA y las formas moleculares de PSA, sobre todo en pacientes que no presentan cifras de PSA muy elevadas. La hK2, una calicreína glandular humana muy parecida al PSA y que también se expresa predominantemente en la próstata, es otro nuevo marcador sérico de cáncer próstata. En esta revisión valoramos el papel del PSA y la hK2 en el diagnóstico precoz de cáncer de próstata.

Palabras clave: Cáncer próstata. PSA. hK2.

\section{ABSTRACT \\ PSA AND hK2 IN THE DIAGNOSIS OF PROSTATE CANCER}

Serum markers for prostate carcinoma are widely applied for the purpose of early detection of cancer and the differentiation between benign and malignant disease, for the pre-treatment staging of detected prostatic cancers, and for the monitoring of prostate cancer after curative or palliative therapies. Since its discovery in 1979, serum PSA has been the most powerful marker of prostate cancer, but, when used alone, PSA is not sufficiently sensitive or specific to consider it an ideal tool for the early detection or staging of prostate cancer. To optimize the use of PSA, the concepts of PSA velocity, PSA density, and age-related PSA values were developed. Moreover, the molecular forms of PSA, especially the percentage of free PSA, seem to be useful tools for the detection of prostate cancer in men with slightly elevated total PSA. Human kallikrein 2 (hK2), a serine protease closely related to PSA that also is expressed predominantly in the prostate, is a new complementary marker to PSA for early detection of prostate cancer. In this review, we examine PSA testing and its effectiveness in the diagnosis of prostate cancer. Further, we also evaluate recent literature regarding the use of hk2.

Keywords: Prostate cancer. PSA. hK2.

$\mathrm{E}^{\mathrm{u}}$ cáncer de próstata (CaP) es el tumor maligno más frecuente en la población masculina de los países industrializados, con una morbilidad y mortalidad considerables. En 2005, se diagnosticaron un total de 232.090 casos nuevos de $\mathrm{CaP}$ en EE.UU., muriendo 30.350 a consecuencia de esta enfermedad ${ }^{1}$. Se trata de un tumor que progresa de manera indetec- table y, en muchas ocasiones, las manifestaciones clínicas sólo aparecen cuando la enfermedad es sistémica. Por lo tanto, el CaP es un problema global importante de salud pública, ante el cual se han desarrollado programas de cribado para la detección precoz ${ }^{2}$.

Desde la década de los 80, el antígeno prostático específico (PSA) ha sido el marcador tumoral más 
utilizado para la detección del CaP, incrementando el número de casos diagnosticados. Sin embargo, el PSA no es específico de CaP y, pese a que se considera un marcador tumoral efectivo y órgano-específico, su aumento no siempre significa que exista $\mathrm{CaP}$, lo cual hace que su especificidad no sea muy elevada. Por esta razón se han desarrollado múltiples parámetros diagnósticos que, basados en el PSA, mejoran la especificidad en la detección precoz del CaP.

En los últimos años varios trabajos han analizado el papel de la hK2 en el diagnóstico de CaP. La hK2 es otra glicoproteína que, al igual que el PSA, pertenece a la familia de las calicreínas humanas y que comparte hasta un $80 \%$ de homología estructural con éste. Al contrario que el PSA, su expresión es mayor en el tejido canceroso que en el benigno.

En el presente trabajo nos proponemos valorar el papel del PSA y de la hK2 en el diagnóstico del CaP.

\section{PSA EN EL DIAGNÓSTICO PRECOZ DEL CANCER DE PRÓSTATA}

También conocido como hK3 o calicreína humana 3, el PSA fue identificado por primera vez por Hara et al. en $1971^{3}$. Es una glicoproteína de cadena única de 33-34 kDa, compuesta por un 93\% de aminoácidos y un $7 \%$ de carbohidratos ${ }^{4}$. Es codificada por el gen hKLK3, que se localiza en el cromosoma $19^{5}$. La expresión de este gen es estimulada principalmente por andrógenos ${ }^{6,7}$, aunque también lo hacen los glucocorticoides y la progesterona, lo que sugiere que los elementos del gen hKLK3 que responden a los esteroides podrían no ser específicos de andrógenos ${ }^{8}$.

Se sintetiza en el epitelio ductal y en los acinos prostáticos $^{9}$. Se encuentra en tejido prostático normal, hiperplásico, tumoral primario y tumoral metastásico de la próstata. Se segrega hacia la luz de los conductos prostáticos mediante exocitosis y se convierte en un componente del plasma seminal, alcanzando el suero tras su difusión desde las células luminares a través de la membrana basal epitelial y del estroma prostático, pudiendo atravesar la membrana basal capilar y las células epiteliales e introducirse en los linfáticos ${ }^{10}$.

A pesar de las suposiciones originales en el sentido de que el PSA era un antígeno con especificidad tisular y especificidad de sexo, los métodos inmunohistoquímicos y de inmunoensayo de alta sensi- bilidad han permitido detectar la presencia de PSA en diversos tejidos y estructuras de la mujer y del hombre como las glándulas periuretrales, glándulas perianales, glándulas sudoríparas apocrinas, carcinomas apocrinos de mama, tumores salivales y en la leche materna. Teniendo en cuenta el descubrimiento de elementos sensibles a los andrógenos en las regiones promotoras del gen codificador de PSA y en los tejidos glandulares en los que se ha demostrado la presencia de PSA, la existencia de PSA en tejidos distintos de la próstata puede reflejar respuestas de órganos terminales a los esteroides circulantes $^{11}$.

El PSA actúa como una proteasa tipo serina, con actividad proteolítica similar a la de la quimotripsina, rompiendo enlaces peptídicos en la región carboxi terminal de ciertos residuos de leucina y tirosina ${ }^{12}$. Es segregado en la luz de la próstata y se introduce en el fluido seminal cuando éste atraviesa la glándula prostática. En el líquido seminal existen proteínas formadoras de gel, principalmente semenogelinas I y II y fibronectina, que son producidas por las vesículas seminales. Estas proteínas son los principales constituyentes del coágulo seminal que se forma en la eyaculación y que actúa atrapando los espermatozoides. El PSA actúa produciendo la licuefacción de este coágulo mediante proteolisis de las proteínas formadoras de gel en fragmentos más pequeños y solubles, liberando de esta forma los espermatozoides ${ }^{13-15}$. Recientemente se ha sugerido que, además, el PSA podría poseer actividad antiangiogénica, gracias a su acción como proteasa tipo serina $^{16}$. El PSA puede inducir proteolisis en el portador principal del factor de crecimiento de tipo insulínico (IGF-1), fijando la proteína 3, y mermando la fijación de IGF-1, lo que puede modular el crecimiento celular y por tanto el CaP.

El PSA se encuentra en el líquido seminal en una concentración elevada (entre 1.000 .000 y 3.000 .000 $\mathrm{ng} / \mathrm{ml}$ ), principalmente en forma libre, mientras que en plasma o suero su concentración es mucho menor (entre 0 y $4 \mathrm{ng} / \mathrm{ml}$ ). En plasma o suero, el PSA se encuentra en diferentes formas moleculares, bien en forma libre, bien formando complejo con diferentes inhibidores plasmáticos. Entre los inhibidores plasmáticos capaces de formar complejos estables y covalentes con el PSA se encuentran la $\alpha_{1}$-antiquimotripsina $\left(\alpha_{1} \mathrm{ACT}\right)$, que forma complejos PSA: $\alpha_{1}$ ACT y la $\alpha_{2}$-macroglobulina $\left(\alpha_{2} \mathrm{M}\right)$, que forma 
complejos PSA: $\alpha_{2} \mathrm{M}^{17-19}$. El PSA en el complejo PSA: $\alpha_{1}$ ACT es enzimáticamente inactivo, mientras que el PSA en el complejo PSA: $\alpha_{2}$ M retiene parte de su actividad enzimática frente a pequeños sustratos 20 . La proporción de PSA libre en el suero oscila entre el 5\% y el 50\% del total medido ${ }^{21}$. Los inmunoensayos disponibles actualmente para el PSA total miden tanto el PSA: $\alpha_{1}$ ACT como el PSA libre, pero no el PSA: $\alpha_{2} M$, ya que la mayoría de los epítopes del PSA se encuentran enmascarados en el complejo PSA: $\alpha_{2}$ M en condiciones de no desnaturalización ${ }^{17}$.

\subsection{LIMITACIONES DEL PSA EN EL DIAGNÓSTICO DEL CANCER DE PROSTÁTA}

Con la introducción del PSA en la práctica clínica, el número de diagnósticos de CaP localizado ha aumentado, mientras que ha habido una disminución en el número de diagnósticos de $\mathrm{CaP}^{22}$. Sin embargo, la especificidad de la prueba del PSA es subóptima y, como resultado de ello, alrededor del $75 \%$ de los hombres que se someten a una biopsia de próstata porque tienen valores de PSA entre 4 y $10 \mathrm{ng} / \mathrm{ml}$ no padecen CaP. Uno de los desafíos decisivos consiste en discriminar entre hiperplasia benigna de próstata (HBP) y CaP. Por este motivo se desarrollaron nuevas fórmulas, basadas todas ellas en la cuantificación sérica de PSA, que en definitiva pretendian incrementar su especificidad con el objetivo de reducir el número de biopsias negativas para CaP, manteniendo una tasa de detección (sensibilidad) similar. Las principales son la densidad de PSA, velocidad de PSA, los rangos específicos por edad y las formas moleculares de PSA.

\subsubsection{Densidad de PSA}

Este término fue introducido por Benson et al. ${ }^{23,24}$ en 1992 para corregir el nivel de PSA en función del tamaño prostático, basándose en que el tejido de CaP libera más PSA por unidad de volumen que el de HBP. La densidad de PSA se define como el cociente entre el PSA total sérico $(\mathrm{ng} / \mathrm{ml})$ y el volumen prostático $\left(\mathrm{cm}^{3}\right)$ medido mediante ecografía transrectal.

Teóricamente, la densidad de PSA podría diferenciar mejor entre HBP y CaP en pacientes con PSA entre 4 y $10 \mathrm{ng} / \mathrm{ml}$ y tacto rectal normal. Sin embargo, la prueba depende de la capacidad del explorador para medir correctamente el volumen prostático. Además, el volumen de la HBP no se relaciona nece- sariamente con los niveles de PSA séricos debido a que la proporción entre epitelio y estroma prostático varía considerablemente entre distintos sujetos y sólo el epitelio produce PSA. Esto explica el amplio solapamiento de valores de densidad de PSA entre pacientes con HBP y CaP. Seaman et al. ${ }^{25}$ refieren que los pacientes con PSA entre 4 y $10 \mathrm{ng} / \mathrm{ml}$ que tienen una densidad de PSA mayor o igual a 0,15 $\mathrm{ng} / \mathrm{ml} / \mathrm{cm}^{3}$ presentan mayor probabilidad de tener un $\mathrm{CaP}$

Por otra parte, Catalona et al. ${ }^{26}$, en el mayor estudio multicéntrico que evalúa la eficacia de la densidad de PSA, refieren que aproximadamente la mitad de los CaP no se diagnostican utilizando este punto de corte de 0,15 ng/ml/año. Brawer et al. ${ }^{27}$, en un estudio de 107 hombres con PSA entre 4 y 10 $\mathrm{ng} / \mathrm{ml}$, no encontraron diferencias estadísticas o clínicas entre aquellos que tenían biopsia prostática positiva y negativa para CaP usando la densidad de PSA.

En un intento de mejorar la especificidad de esta prueba surgió la densidad de PSA de la zona de transición (PSA/Volumen zona de transición). Se basa en que la HBP se localiza exclusivamente en la zona transicional. Djavan et al. ${ }^{28}$ refieren que con un punto de corte de $0,35 \mathrm{ng} / \mathrm{ml} / \mathrm{cm}^{3}$ obtienen un valor predictivo positivo del $74 \%$ en la detección de CaP en 939 hombres con PSA menor de 10 ng/ml. Sin embargo, también presenta la limitación de que depende de las variaciones intra e interobservador de la ecografía transrectal y además existe una falta de reproductividad entre centros.

\subsubsection{Velocidad de PSA}

Carter et al. ${ }^{29}$ introdujeron este concepto en 1992 para mejorar la capacidad del PSA para detectar CaP. Se basa en el incremento de la concentración de PSA total con relación al tiempo, teóricamente mayor en el CaP que en la HBP, ya que las variaciones volumétricas del epitelio prostático son más rápidas cuando éste es tumoral.

Se calcula con la siguiente fórmula: $1 / 2 *\left(\left[\mathrm{PSA}_{2}-\right.\right.$ $\mathrm{PSA}_{1} /$ tiempo $_{1}$ en años]+[PSA ${ }_{3}-\mathrm{PSA}_{2} /$ tiempo $_{2}$ en años]), donde $\mathrm{PSA}_{1}$ es la primera, $\mathrm{PSA}_{2}$ la segunda $\mathrm{y}$ $\mathrm{PSA}_{3}$ la tercera medición de PSA realizada en un periodo de 2 años. Carter et al. (29) establecieron que una velocidad de PSA $\geq 0,75 \mathrm{ng} / \mathrm{ml} /$ año es muy sugestiva de la presencia de $\mathrm{CaP}$ (72\% de sensibilidad y $95 \%$ de especificidad). 
Las limitaciones que presenta son que es difícil de calcular, que el PSA no es específico de CaP y que el PSA varía significativamente con el tiempo y con los diferentes ensayos de medición, con lo que no puede ser usado como método de screening rutinario de CaP. Sin embargo, sí es válido para seguimiento a largo plazo de pacientes de bajo riesgo y en las rebiopsias prostáticas.

\subsubsection{Rangos de referencia especificos de edad}

Este concepto fue introducido por Oesterling et al. ${ }^{30}$ y se basa en que el PSA aumenta a medida que lo hace la edad. La explicación más lógica de esta relación es que el tamaño prostático aumenta con la edad, aumentando la producción de PSA y su paso al torrente sanguíneo.

Diferentes estudios han establecido diferentes valores de PSA para cada grupo de edad (Tabla 1). La finalidad es mejorar la sensibilidad en el diagnóstico de $\mathrm{CaP}$ en sujetos menores de 60 años y la especificidad en los mayores. Estos rangos aumentarían el número de $\mathrm{CaP}$ en sujetos jóvenes (con $\mathrm{CaP}$ organoconfinado, beneficiándose por tanto de un tratamiento curativo) y evitarian el tratamiento innecesario de sujetos mayores con tumores clínicamente insignificantes. Varios estudios han confirmado esto ${ }^{31-34}$. Sin embargo, y como podemos apreciar en la tabla 1, existe una gran variabilidad en los puntos de corte de PSA para cada grupo de edad. Además, el aumento de la especificidad que proporciona el PSA-edad en los sujetos mayores de 60 años conlleva una pérdida en el diagnóstico de un $20-30 \%$ de $\mathrm{CaP}^{35,36}$.

\subsubsection{Formas moleculares de PSA}

Como se ha indicado anteriormente, el PSA sérico se encuentra en forma libre o unido a diversos inhibidores plasmáticos. La $\alpha_{1} \mathrm{ACT}$ forma complejos irreversibles con la mayor parte del PSA activo en suero, mientras que la $\alpha_{2} \mathrm{M}$, la $\alpha_{1}$-antitripsina $\left(\alpha_{1} \mathrm{AT}\right)$ $\mathrm{y}$ otras proteínas se unen en menor cantidad ${ }^{37}$. Los ensayos comerciales disponibles permiten detectar la concentración de PSA total, de complejo PSA: $\alpha_{1}$ ACT y de PSA libre. Sin embargo, el PSA unido a la $\alpha_{2} \mathrm{M}$ es inmunológicamente indetectable debido a que el gran tamaño de esta proteína encapsula casi completamente la molécula de PSA y bloquea todos sus epítopos.
Tabla 1. Rangos de referencia de edad específicos (PSAedad)

\begin{tabular}{lcccc}
\hline \multirow{2}{*}{ Referencia } & \multicolumn{4}{c}{ Edad (años) } \\
& $\mathbf{4 0 - 4 9}$ & $\mathbf{5 0 - 5 9}$ & $\mathbf{6 0 - 6 9}$ & $\mathbf{7 0 - 7 9}$ \\
\hline Oesterling $^{34}$ & 2,0 & 3,0 & 4,0 & 5,5 \\
DeAntoni $^{31}$ & 2,3 & 3,8 & 5,6 & 6,9 \\
Morgan $^{33}$ & 2,1 & 3,6 & 4,3 & 5,8 \\
Lein $^{32}$ & 1,75 & 2,27 & 3,48 & 4,26 \\
\hline \multicolumn{4}{c}{ PSA (ng/ml) } \\
\hline
\end{tabular}

En un intento de mejorar el diagnóstico de CaP, se han estudiado las diferentes formas moleculares del PSA.

\subsubsection{PSA libre}

La proporción del PSA libre respecto al PSA total fue el primer ensayo basado en las distintas formas de PSA y surgió cuando se desarrollaron anticuerpos que detectaron el PSA libre.

El porcentaje de PSA libre es superior en pacientes con $\mathrm{HBP}$ que en aquellos con $\mathrm{CaP}^{38}$. Este incremento podría ser debido a diferentes mecanismos de producción de $\alpha_{1} \mathrm{ACT}$ en el tejido hiperplásico y en el maligno, así como al diferente paso del PSA prostático a la circulación debido a la pérdida de la arquitectura tisular del CaP.

En general, existe un acuerdo en que el PSA libre logra una mejor discriminación entre HBP y $\mathrm{CaP}$ que el PSA total. Varios estudios que investigan el rendimiento del cociente PSA libre/PSA total han mostrado que, a pesar de las diferencias en los ensayos de PSA utilizados, existe una coincidencia relativa en el rendimiento global de la tasa en términos de sensibilidad y especificidad. El punto de corte para la tasa del cociente PSA libre/PSA total difiere de forma significativa entre ensayos (Tablas 2 y 3). Estas variaciones podrían ser debidas a los diferentes diseños de cada estudio y a diferencias en las poblaciones sujetas a estudio ${ }^{39}$. Sin embargo, el ensayo parece útil a la hora de ayudar a determinar qué pacientes con un PSA ligeramente elevado no necesitan ser sometidos a biopsia.

El porcentaje de PSA libre se debe aplicar a pacientes con un PSA total menor de $10 \mathrm{ng} / \mathrm{ml}$, ya que con PSA total mayor a $10 \mathrm{ng} / \mathrm{ml}$ aparece CaP en más de la mitad de los casos y la mejora en la especificidad disminuye significativamente la sensibilidad. 
Tabla 2. Estudios sobre la utilidad clínica del cociente PSA libre/PSA total en el diagnóstico de CaP en pacientes con rango de PSA total entre 4 y $10 \mathrm{ng} / \mathrm{ml}$.

\begin{tabular}{|c|c|c|c|c|c|}
\hline Referencia & $\begin{array}{l}\text { Año } \\
\text { País }\end{array}$ & $\begin{array}{c}\mathbf{N}^{\circ} \text { Biopsias } \\
\mathbf{N}^{\circ} \text { CaP }\end{array}$ & $\begin{array}{c}\text { Sensibilidad } \\
\%\end{array}$ & $\begin{array}{c}\text { Especificidad } \\
\%\end{array}$ & $\begin{array}{c}\text { Valor } \\
\text { Corte (\%) }\end{array}$ \\
\hline Catalona et $\mathrm{al}^{94}$ & $\begin{array}{c}1995 \\
\text { EEUU }\end{array}$ & $\begin{array}{c}113 \\
50\end{array}$ & $\begin{array}{l}90 \\
80\end{array}$ & $\begin{array}{c}38,1 \\
50\end{array}$ & $\begin{array}{c}20,3 \\
-\end{array}$ \\
\hline Morote et $\mathrm{al}^{95}$ & $\begin{array}{c}1997 \\
\text { España }\end{array}$ & $\begin{array}{l}74 \\
22\end{array}$ & $\begin{array}{l}95,5 \\
77,3\end{array}$ & $\begin{array}{l}26,9 \\
36,5\end{array}$ & $\begin{array}{l}25 \\
20\end{array}$ \\
\hline Bangma et $\mathrm{al}^{96}$ & $\begin{array}{c}1997 \\
\text { Holanda }\end{array}$ & $\begin{array}{r}497 \\
99\end{array}$ & $\begin{array}{l}91 \\
87 \\
83\end{array}$ & $\begin{array}{l}36 \\
46 \\
55\end{array}$ & $\begin{array}{l}22 \\
20 \\
18\end{array}$ \\
\hline Brawer et al ${ }^{97}$ & $\begin{array}{c}1998 \\
\text { EE.UU }\end{array}$ & $\begin{array}{c}153 \\
36\end{array}$ & $\begin{array}{r}100 \\
95 \\
90\end{array}$ & $\begin{array}{r}4,4 \\
11,4 \\
19,3\end{array}$ & $\begin{array}{l}34 \\
29 \\
24\end{array}$ \\
\hline España et $\mathrm{al}^{47}$ & $\begin{array}{c}1998 \\
\text { España }\end{array}$ & $\begin{array}{l}61 \\
15\end{array}$ & $\begin{array}{r}100 \\
95 \\
86\end{array}$ & $\begin{array}{l}28 \\
28 \\
28\end{array}$ & $\begin{array}{l}28 \\
27 \\
26\end{array}$ \\
\hline Kuriyama et $\mathrm{al}^{98}$ & $\begin{array}{l}1998 \\
\text { Japón }\end{array}$ & $\begin{array}{r}121 \\
36\end{array}$ & $\begin{array}{l}90 \\
85\end{array}$ & $\begin{array}{l}19 \\
57\end{array}$ & $\begin{array}{l}23 \\
17\end{array}$ \\
\hline Partin et $\mathrm{al}^{99}$ & $\begin{array}{c}1998 \\
\text { EEUU }\end{array}$ & $\begin{array}{c}219 \\
31\end{array}$ & 95 & 20 & 61 \\
\hline Brawer et $\mathrm{al}^{50}$ & $\begin{array}{l}2000 \\
\text { EEUU }\end{array}$ & $\begin{array}{l}439 \\
202\end{array}$ & $\begin{array}{l}95 \\
90 \\
85\end{array}$ & $\begin{array}{l}17 \\
25 \\
34\end{array}$ & $\begin{array}{c}23 \\
20,5 \\
18,9\end{array}$ \\
\hline Martínez-Piñeiro et al ${ }^{100}$ & $\begin{array}{c}2000 \\
\text { España }\end{array}$ & $\begin{array}{c}180 \\
40\end{array}$ & $\begin{array}{l}95 \\
90 \\
85\end{array}$ & $\begin{array}{l}32,1 \\
39,3 \\
42,9\end{array}$ & $\begin{array}{l}22 \\
20 \\
19\end{array}$ \\
\hline Okegawa et $\mathrm{al}^{42}$ & $\begin{array}{l}2000 \\
\text { Japón }\end{array}$ & $\begin{array}{c}162 \\
30\end{array}$ & $\begin{array}{l}96 \\
91 \\
83\end{array}$ & $\begin{array}{l}23 \\
33 \\
45\end{array}$ & $\begin{array}{l}22 \\
18 \\
14\end{array}$ \\
\hline Hofer et $\mathrm{al}^{36}$ & $\begin{array}{l}2000 \\
\text { EEUU }\end{array}$ & $\begin{array}{l}330 \\
112\end{array}$ & $\begin{array}{l}96 \\
91 \\
87\end{array}$ & $\begin{array}{l}35 \\
44 \\
58\end{array}$ & $\begin{array}{l}25 \\
21 \\
18\end{array}$ \\
\hline Vesella et $\mathrm{al}^{101}$ & $\begin{array}{c}2000 \\
\text { EEUU }\end{array}$ & $\begin{array}{l}297 \\
100\end{array}$ & $\begin{array}{l}96 \\
90 \\
35\end{array}$ & $\begin{array}{l}27,4 \\
40,1 \\
90,4\end{array}$ & $\begin{array}{l}26,4 \\
23,6 \\
11,2\end{array}$ \\
\hline Okihara et $\mathrm{al}^{55}$ & $\begin{array}{c}2002 \\
\text { EEUU }\end{array}$ & $\begin{array}{c}210 \\
71\end{array}$ & $\begin{array}{l}95 \\
90 \\
85\end{array}$ & $\begin{array}{l}23 \\
39 \\
47\end{array}$ & $\begin{array}{l}21 \\
19 \\
18\end{array}$ \\
\hline Saika et al ${ }^{43}$ & $\begin{array}{l}2002 \\
\text { Japón }\end{array}$ & $\begin{array}{r}221 \\
58\end{array}$ & $\begin{array}{l}95 \\
90 \\
80\end{array}$ & $\begin{array}{l}23,1 \\
32,9 \\
45,7\end{array}$ & $\begin{array}{l}24 \\
20 \\
17\end{array}$ \\
\hline Haese et $\mathrm{al}^{102}$ & $\begin{array}{l}2002 \\
\text { EEUU }\end{array}$ & $\begin{array}{l}756 \\
226\end{array}$ & $\begin{array}{l}99,1 \\
96,6 \\
90,7\end{array}$ & $\begin{array}{r}3,6 \\
12,1 \\
23,6\end{array}$ & $\begin{array}{l}34 \\
28 \\
24\end{array}$ \\
\hline Djavan et al ${ }^{53}$ & $\begin{array}{c}2002 \\
\text { Europa }\end{array}$ & $\begin{array}{l}340 \\
103\end{array}$ & $\begin{array}{l}95 \\
90 \\
85\end{array}$ & $\begin{array}{r}7,7 \\
26,9 \\
26,9\end{array}$ & $\begin{array}{c}7,1 \\
9 \\
10,5\end{array}$ \\
\hline Partin et $\mathrm{al}^{51}$ & $\begin{array}{c}2003 \\
\text { EEUU } \\
\text { Austria }\end{array}$ & $\begin{array}{l}391 \\
181\end{array}$ & $\begin{array}{l}95 \\
90 \\
85\end{array}$ & $\begin{array}{c}11 \\
21,5 \\
26\end{array}$ & $\begin{array}{c}21 \\
18,5 \\
17\end{array}$ \\
\hline Okihara et $\mathrm{al}^{40}$ & $\begin{array}{l}2004 \\
\text { Japón }\end{array}$ & $\begin{array}{c}116 \\
40\end{array}$ & $\begin{array}{c}95 \\
90 \\
85\end{array}$ & $\begin{array}{r}6,6 \\
13,2 \\
23,7\end{array}$ & $\begin{array}{l}35,3 \\
28,3 \\
23,6\end{array}$ \\
\hline
\end{tabular}


Tabla 3. Estudios sobre la utilidad clínica del cociente PSA libre/PSA total en el diagnóstico de CaP en pacientes con rango de PSA total $<4 \mathrm{ng} / \mathrm{ml}$.

\begin{tabular}{|c|c|c|c|c|c|c|}
\hline Referencia & $\begin{array}{l}\text { Año } \\
\text { País }\end{array}$ & $\begin{array}{c}\mathbf{N}^{\circ} \text { Biopsias } \\
\mathbf{N}^{\circ} \mathrm{CaP}\end{array}$ & $\begin{array}{c}\text { Rango } \\
\text { PSA } \\
\text { (ng/ml) }\end{array}$ & $\begin{array}{c}\text { Sensibilidad } \\
\text { (\%) }\end{array}$ & $\begin{array}{c}\text { Especificidad } \\
(\%)\end{array}$ & $\begin{array}{c}\text { Valor } \\
\text { Corte } \\
(\%)\end{array}$ \\
\hline Catalona et al. ${ }^{103}$ & $\begin{array}{c}1997 \\
\text { EEUU }\end{array}$ & $\begin{array}{c}332 \\
73\end{array}$ & $2,6-4$ & 90 & 8 & 27 \\
\hline Prestiagiacomo et al. ${ }^{104}$ & $\begin{array}{c}1997 \\
\text { EEUU }\end{array}$ & $\begin{array}{l}29 \\
10\end{array}$ & $2,5 / 4$ & $\begin{array}{l}90 \\
80\end{array}$ & $\begin{array}{l}20 \\
40\end{array}$ & $\begin{array}{l}30 \\
24\end{array}$ \\
\hline Catalona et al. ${ }^{105}$ & $\begin{array}{c}1999 \\
\text { EEUU }\end{array}$ & $\begin{array}{c}368 \\
54\end{array}$ & $2,5-4$ & $\begin{array}{l}54 \\
50\end{array}$ & $\begin{array}{l}68 \\
72\end{array}$ & $\begin{array}{l}15 \\
14\end{array}$ \\
\hline Djavan et al. ${ }^{106}$ & $\begin{array}{c}1999 \\
\text { Austria } \\
\text { Bélgica }\end{array}$ & $\begin{array}{c}273 \\
66\end{array}$ & $2,5-4$ & $\begin{array}{l}93,9 \\
71,2\end{array}$ & $\begin{array}{l}39,6 \\
64,7\end{array}$ & $\begin{array}{l}40 \\
30\end{array}$ \\
\hline Okihara et al. ${ }^{60}$ & $\begin{array}{c}2001 \\
\text { EEUU }\end{array}$ & $\begin{array}{c}151 \\
37\end{array}$ & $2,5-4$ & $\begin{array}{c}100 \\
95 \\
89\end{array}$ & $\begin{array}{c}3 \\
11 \\
11\end{array}$ & $\begin{array}{l}44 \\
31 \\
30\end{array}$ \\
\hline Haese et al. ${ }^{102}$ & $\begin{array}{l}2002 \\
\text { EEUU }\end{array}$ & $\begin{array}{c}217 \\
41\end{array}$ & $2-4$ & $\begin{array}{l}95,1 \\
90,2 \\
85,4\end{array}$ & $\begin{array}{l}13,5 \\
21,9 \\
25,8\end{array}$ & $\begin{array}{l}34 \\
30 \\
28\end{array}$ \\
\hline Roehl et al. ${ }^{107}$ & $\begin{array}{c}2002 \\
\text { EEUU }\end{array}$ & $\begin{array}{l}965 \\
241\end{array}$ & $2,6-4$ & $\begin{array}{l}93 \\
85\end{array}$ & $\begin{array}{c}9 \\
19\end{array}$ & $\begin{array}{l}30 \\
25\end{array}$ \\
\hline Horninger et al. ${ }^{108}$ & $\begin{array}{c}2002 \\
\text { EEUU }\end{array}$ & $\begin{array}{c}308 \\
58\end{array}$ & $2-4$ & $\begin{array}{l}90 \\
85\end{array}$ & $\begin{array}{l}23 \\
35\end{array}$ & - \\
\hline Lein et al. ${ }^{58}$ & $\begin{array}{l}2003 \\
\text { Japón }\end{array}$ & $\begin{array}{l}230 \\
112\end{array}$ & $2,5-4$ & $\begin{array}{l}95 \\
90 \\
85\end{array}$ & $\begin{array}{c}6 \\
12,7 \\
19,5\end{array}$ & $\begin{array}{c}28 \\
25,2 \\
22,1\end{array}$ \\
\hline Partin et al. ${ }^{51}$ & $\begin{array}{c}2003 \\
\text { EEUU } \\
\text { Austria }\end{array}$ & $\begin{array}{c}214 \\
54\end{array}$ & $2-4$ & $\begin{array}{l}95 \\
90 \\
85\end{array}$ & $\begin{array}{l}7,5 \\
20 \\
26\end{array}$ & $\begin{array}{c}27,5 \\
21 \\
20\end{array}$ \\
\hline Kobayashi et al. ${ }^{41}$ & $\begin{array}{c}2005 \\
\text { Japón }\end{array}$ & $\begin{array}{c}116 \\
27\end{array}$ & $2-4$ & $\begin{array}{l}95 \\
90 \\
80\end{array}$ & $\begin{array}{c}18 \\
37,1 \\
50,6\end{array}$ & $\begin{array}{c}29 \\
37,1 \\
50,6\end{array}$ \\
\hline
\end{tabular}

\subsubsection{PSA formando complejos PSA: $\alpha_{1}$ ACT}

La proporción de PSA que forma complejos con $\alpha_{1} \mathrm{ACT}$ es significativamente mayor en el CaP que en la $\mathrm{HBP}^{18}$, por lo que utilizando el cociente PSA: $\alpha_{1}$ ACT/PSA total o el complejo PSA: $\alpha_{1}$ ACT en lugar del PSA total, se podría discriminar mejor ambas patologías. Así, en los últimos años han sido numerosos los trabajos aparecidos en la literatura que han constatado la eficacia diagnóstica de estos parámetros en el diagnóstico del CaP (Tablas 4 y 5). En el rango de PSA entre 4 y $10 \mathrm{ng} / \mathrm{ml}$, Okihara et al. ${ }^{40} \mathrm{y}$ Kobayashi et al. ${ }^{41}$ refieren que el complejo PSA: $\alpha_{1}$ ACT no discrimina mejor el $\mathrm{CaP}$ que el PSA total. Okegawa et al. ${ }^{42}$ tan sólo pudieron demostrar diferencias significativas cuando se comparaba el PSA total con el cociente PSA: $\alpha_{1}$ ACT/PSA total. Sin embargo, Saika et al. ${ }^{43}$ sí que encontraron diferencias significativas y para una sensibilidad del 90\% obtuvieron especificidades del 10,8\% para PSA total y $31,7 \%$ para el PSA: $\alpha_{1}$ ACT

Las investigaciones realizadas por nuestro grupo, a diferencia de otros autores ${ }^{44}$, revelan que el porcentaje de PSA formando complejo con $\alpha_{1}$ ACT es más eficaz que el porcentaje de PSA libre para diferenciar la $\mathrm{HBP}$ y el $\mathrm{CaP}$ en el rango de PSA total entre 2 y $10 \mathrm{ng} / \mathrm{ml}$ y que su uso es preferible al uso del porcentaje de PSA libre ${ }^{45-47}$. Además, el porcentaje de PSA acomplejado mostró mayor discriminación entre CaP e HBP que el de PSA libre en los rangos de PSA entre 2 y $4 \mathrm{ng} / \mathrm{ml}^{48}$ y entre 10 y 30 $\mathrm{ng} / \mathrm{ml}$ de PSA total ${ }^{49}$. 
Tabla 4. Estudios sobre la utilidad clínica del PSA en forma de complejo en el diagnóstico de CaP en pacientes con rango de PSA total entre 4 y $10 \mathrm{ng} / \mathrm{ml}$.

\begin{tabular}{|c|c|c|c|c|c|c|}
\hline & Referencia & $\begin{array}{l}\text { Año } \\
\text { País }\end{array}$ & $\begin{array}{c}\mathbf{N}^{\circ} \text { Biopsias } \\
\mathbf{N}^{\circ} \text { CaP }\end{array}$ & $\begin{array}{c}\text { Sensibilidad } \\
\text { (\%) }\end{array}$ & $\begin{array}{c}\text { Especificidad } \\
(\%)\end{array}$ & $\begin{array}{c}\text { Valor } \\
\text { corte (\%) }\end{array}$ \\
\hline \multirow{24}{*}{ 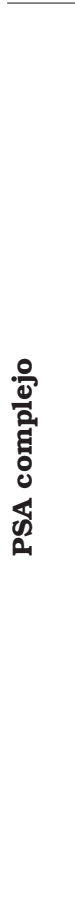 } & Brawer et al. ${ }^{97}$ & 1998 & 153 & 100 & 7 & 3,26 \\
\hline & & EEUU & 36 & 95 & 7,9 & 3,36 \\
\hline & & & & 90 & 25,4 & 3,92 \\
\hline & Maeda et al. ${ }^{109}$ & 1999 & 137 & 100 & 11 & 2,6 \\
\hline & & Japón & 23 & 96 & 15 & 2,9 \\
\hline & & & & 87 & 42 & 4,1 \\
\hline & Brawer et al. ${ }^{50}$ & 2000 & 439 & 95 & 18 & 3,7 \\
\hline & & & 202 & 90 & 25 & 3,94 \\
\hline & & & & 85 & 31 & 4,19 \\
\hline & Okegawa et al. ${ }^{110}$ & 2000 & 140 & 96 & 18 & 3,9 \\
\hline & & Japón & 24 & 92 & 24 & 4,6 \\
\hline & & & & 83 & 38 & 5 \\
\hline & Djavan et al. ${ }^{53}$ & 2002 & 340 & 95 & 9,1 & 2,52 \\
\hline & & Europa & 103 & 90 & 20,3 & 3,06 \\
\hline & & & & 85 & 26,7 & 3,33 \\
\hline & Okihara et al. ${ }^{55}$ & 2002 & 210 & 95 & 5 & 3,5 \\
\hline & & EEUU & 71 & 90 & 9 & 3,72 \\
\hline & & & & 85 & 10 & 3,81 \\
\hline & Partin et al. ${ }^{51}$ & 2003 & 391 & 95 & 6,8 & 3,36 \\
\hline & & EEUU & 181 & 90 & 13,3 & 3,58 \\
\hline & & Austria & & 85 & 18,6 & 3,66 \\
\hline & Okihara et al. ${ }^{40}$ & 2004 & 116 & 95 & 14,5 & 2,8 \\
\hline & & Japón & 40 & 90 & 21,3 & 2,89 \\
\hline & & & & 85 & 22,1 & 3 \\
\hline \multirow{12}{*}{ 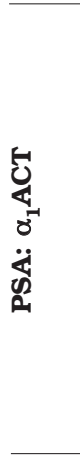 } & Okegawa et al. ${ }^{42}$ & 2000 & 162 & 96 & 24 & 3,8 \\
\hline & & Japón & 30 & 91 & 32 & 4,6 \\
\hline & & & & 83 & 39 & 5 \\
\hline & Saika et al. ${ }^{43}$ & 2002 & 221 & 95 & 8,5 & 3,3 \\
\hline & & Japón & 58 & 90 & 31,7 & 4 \\
\hline & & & & 80 & 36 & 4,3 \\
\hline & Okihara et al. ${ }^{40}$ & 2004 & 116 & 95 & 13,2 & 2,85 \\
\hline & & Japón & 40 & 90 & 22,4 & 3,05 \\
\hline & & & & 85 & 27,6 & 3,15 \\
\hline & Kobayashi et al. ${ }^{41}$ & 2005 & 139 & 95 & 8,9 & 2,7 \\
\hline & & Japón & 37 & 90 & 18,8 & 3 \\
\hline & & & & 80 & 30,7 & 3,3 \\
\hline \multirow{12}{*}{ 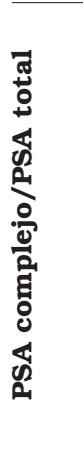 } & Djavan et al. ${ }^{53}$ & 2002 & 340 & 95 & 11,8 & 70,5 \\
\hline & & Europa & 103 & 90 & 17,7 & 74 \\
\hline & & & & 85 & 25,9 & 76 \\
\hline & Okihara et al. ${ }^{55}$ & 2002 & 210 & 95 & 25 & 77 \\
\hline & & EEUU & 71 & 90 & 33 & 80 \\
\hline & & & & 85 & 41 & 82 \\
\hline & Partin et al. ${ }^{51}$ & 2003 & 391 & 95 & 13,3 & 74,5 \\
\hline & & EEUU & 181 & 90 & 21,9 & 77,5 \\
\hline & & Austria & & 85 & 28 & 79 \\
\hline & Kobayashi et al. ${ }^{41}$ & 2005 & 139 & 95 & 7,9 & 52 \\
\hline & & Japón & 37 & 90 & 28,7 & 60 \\
\hline & & & & 80 & 38,6 & 64 \\
\hline \multirow{6}{*}{ 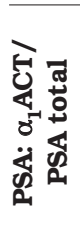 } & Okegawa et al. ${ }^{42}$ & 2000 & 162 & 96 & 33 & 77 \\
\hline & & Japón & 30 & 91 & 50 & 85 \\
\hline & & & & 83 & 59 & 90 \\
\hline & Okihara et al. ${ }^{40}$ & 2004 & 116 & 95 & 5,3 & 49,4 \\
\hline & & Japón & 40 & 90 & 14,5 & 54,4 \\
\hline & & & & 85 & 25 & 58 \\
\hline
\end{tabular}


Tabla 5. Estudios sobre la utilidad clínica del PSA en forma de complejo en el diagnóstico de CaP en pacientes con PSA total $<4 \mathrm{ng} / \mathrm{ml}$.

\begin{tabular}{|c|c|c|c|c|c|c|c|}
\hline & Referencia & $\begin{array}{l}\text { Año } \\
\text { País }\end{array}$ & $\begin{array}{c}\mathbf{N}^{\circ} \text { biopsias } \\
\mathbf{N}^{\circ} \mathbf{C a P}\end{array}$ & $\begin{array}{c}\text { Rango } \\
\text { PSA } \\
\text { (ng/ml) }\end{array}$ & $\begin{array}{c}\text { Sensibilidad } \\
\text { (\%) }\end{array}$ & $\begin{array}{c}\text { Especificidad } \\
\text { (\%) }\end{array}$ & $\begin{array}{c}\text { Valor } \\
\text { corte } \\
(\mathrm{ng} / \mathrm{ml})\end{array}$ \\
\hline \multirow{14}{*}{ 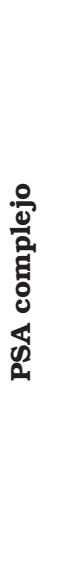 } & Okihara et al. ${ }^{60}$ & 2001 & 151 & $2,4-4$ & 95 & 38 & 2,19 \\
\hline & & EEUU & 37 & & 92 & 42 & 2,30 \\
\hline & & & & & 89 & 42 & 2,32 \\
\hline & Horninger et al. ${ }^{108}$ & 2002 & 308 & $2-4$ & 90 & 20 & - \\
\hline & & EEUU & 58 & & 85 & 34 & - \\
\hline & Partin et al. ${ }^{51}$ & 2003 & 214 & $2-4$ & 95 & 5,6 & 1,65 \\
\hline & & EEUU & 54 & & 90 & 20 & 1,92 \\
\hline & & Austria & & & 85 & 35 & 2,24 \\
\hline & Lein et al. ${ }^{58}$ & 2003 & 230 & $2,5-4$ & 95 & 1 & 1,61 \\
\hline & & Japón & 112 & & 90 & 4 & 1,74 \\
\hline & & & & & 85 & 16,9 & 2,01 \\
\hline & Parson et al. ${ }^{57}$ & 2004 & 316 & $2,6-4$ & 95 & 20,1 & 2,27 \\
\hline & & EEUU & 82 & & 90 & 25,6 & 2,35 \\
\hline & & Austria & & & 85 & 32,5 & 2,41 \\
\hline \multirow{3}{*}{ 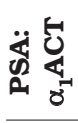 } & Kobayashi et al. ${ }^{41}$ & 2005 & 116 & $2-4$ & 95 & 36 & 1,6 \\
\hline & & Japón & 27 & & 90 & 40,4 & 1,7 \\
\hline & & & & & 80 & 52,8 & 1,8 \\
\hline \multirow{6}{*}{ 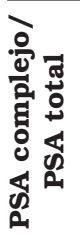 } & Partin et al. ${ }^{51}$ & 2003 & 214 & $2-4$ & 95 & 9 & 66 \\
\hline & & EEUU & 54 & & 90 & 20 & 72 \\
\hline & & Austria & & & 85 & 25 & 74 \\
\hline & Okihara et al. ${ }^{60}$ & 2001 & 151 & $2,5-4$ & 95 & 17 & 73 \\
\hline & & EEUU & 37 & & 92 & 21 & 75 \\
\hline & & & & & 89 & 33 & 79 \\
\hline \multirow{6}{*}{ 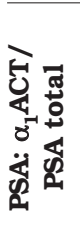 } & Martínez et al. ${ }^{48}$ & 2000 & 227 & $2-4$ & 100 & 12,8 & 49 \\
\hline & & España & 34 & & 94 & 75 & 73 \\
\hline & & & & & 91 & 80,7 & 75 \\
\hline & Kobayashi et al. ${ }^{41}$ & 2005 & 116 & $2-4$ & 95 & 38,2 & 59 \\
\hline & & Japón & 27 & & 90 & 40,4 & 60 \\
\hline & & & & & 80 & 50,6 & 64 \\
\hline
\end{tabular}

Con valores de PSA total menor a $4 \mathrm{ng} / \mathrm{ml}$, Kobayashi et al. ${ }^{41}$, en una serie de 116 pacientes $(27$ con $\mathrm{CaP}$ ), refieren que el $\mathrm{ABC}$ tanto del complejo PSA: $\alpha_{1}$ ACT como del cociente PSA: $\alpha_{1}$ ACT/PSA total fueron significativamente mayores que la del PSA total, con especificidades también mayores. Para un 95\% de sensibilidad con el complejo PSA: $\alpha_{1}$ ACT y el cociente PSA: $\alpha_{1}$ ACT/PSA total se consiguieron especificidades del 36\% y 38,8\% respectivamente. Para un 90\% de sensibilidad, las especificidades fueron similares y consiguieron aumentar a la del PSA total del 25,85 al 40,4\%, disminuyendo el número de biopsias necesarias para detectar un CaP de 7,5 a 6. Martínez et al. ${ }^{48}$, en una serie de 227 pacientes (34 de ellos con $\mathrm{CaP}$, demostraron que el cociente PSA: $\alpha_{1} \mathrm{ACT} / \mathrm{PSA}$ total mejora la sensibilidad del PSA total, detectando más cánceres potencialmente curables.

\section{PSA complejo}

Varios autores han analizado el valor de esta forma molecular de PSA en el diagnóstico de $\mathrm{CaP}$ (Tablas 4 y 5). Brawer et al. ${ }^{50}$, utilizando un ensayo que mide todo el PSA unido a sus diferentes inhibidores plasmáticos (PSA complejo), analizaron si la medida del PSA complejo podía ser una alternativa al porcentaje de PSA libre. Para ello utilizaron las muestras de PSA de 385 pacientes con biopsia prostática negativa y 272 con biopsia positiva, con rangos entre 0,32 y $117 \mathrm{ng} / \mathrm{ml}$. El área bajo la curva del porcentaje de PSA libre fue superior a la del PSA complejo y a la del PSA libre. Sin embargo, para una sensibilidad entre $85 \%$ y 95\%, la especificidad fue mayor para el PSA complejo que para el porcentaje de PSA libre, y equivalente a la del PSA libre. Lo mismo ocurrió en el rango de PSA entre 4 y 10 ng/ml. 
Sin embargo, en los casos con PSA entre 4 y 6 $\mathrm{ng} / \mathrm{ml}$ la especificidad del PSA complejo fue superior a la del porcentaje de PSA libre. La conclusión de este estudio fue que el PSA complejo puede ser una alternativa al uso del porcentaje de PSA libre, aunque la población identificada por ambos ensayos es diferente. Estos resultados coinciden con los de otros autores ${ }^{51-54}$. Sin embargo, Okihara et al. y Stamey y Yemoto ${ }^{55,56}$ no encuentran estas diferencias y refieren que el PSA complejo no muestra ninguna ventaja con respecto al uso del PSA total. Posteriormente, el grupo de Okihara, en un estudio en población Japonesa, refiere que el PSA complejo sí que puede mejorar la detección de CaP comparado con el PSA total pero no en este rango de PSA ${ }^{40}$.

Parsons et al. ${ }^{57}$, en el mayor estudio multicéntrico realizado que analiza el valor del PSA complejo cuando el PSA total es menor a $4 \mathrm{ng} / \mathrm{ml}$, refieren que este parámetro aumenta la especificidad de manera considerable con respecto al PSA total, y a valores equiparables a los del cociente PSA libre/PSA total. Para sensibilidades del 90\% y 95\% con el PSA complejo obtienen especificidades de $25,6 \%$ y $20,1 \%$ respectivamente, mientras que con el PSA total serían de $11,1 \%$ y $9,8 \%$. Sin embargo, Lein et al. ${ }^{58} \mathrm{y}$ Jung et al. ${ }^{59}$ no encuentran ventajas del PSA complejo con respecto al PSA total, aunque las poblaciones estudiadas y los ensayos para medir el PSA total fueron distintos. Lein et al. ${ }^{58}$ sí que describen estas ventajas cuando analizan el cociente PSA complejo/PSA total. Otros autores que han estudiado este cociente refieren que no aporta mejores resultados que el PSA complejo ${ }^{51,60}$.

\section{PSA: $\alpha_{2} M$}

Esta fracción de PSA no se detecta con los inmunoensayos de PSA convencionales debido a que la $\alpha_{2} \mathrm{M}$ encapsula los epítopos de la molécula del PSA. Sin embargo, si se desnaturaliza el complejo reduciéndolo con ditiotreitol ${ }^{61}$ o elevando el $\mathrm{pH}$ a $11,4^{62}$ se puede cuantificar el complejo PSA: $\alpha_{2} \mathrm{M}$.

Zhang et al. en el $2000^{63}$ desarrollaron un algoritmo basado en el PSA: $\alpha_{2} \mathrm{M}$ y PSA libre ([PSA: $\alpha_{2} \mathrm{M}$ /(PSA total + PSA: $\left.\alpha_{2} M\right)+$ porcentaje de PSA libre] $x$ 100) para distinguir los pacientes con HBP de los de CaP. El ABC para este algoritmo fue significativamente mayor que la del PSA total. Para una sensibilidad del $100 \%$ la especificidad fue del $56 \%$, disminuyendo el número de biopsias innecesarias en más de un $50 \%$ sin perder ningún CaP. Nuestro grupo, con una serie más numerosa (124 CaP y 464 patología benigna), no ha podido reproducir estos resultados y no hemos conseguido especificidades mayores a las obtenidas con los porcentajes de PSA libre y PSA: $\alpha_{1}$ ACT para ningún valor de sensibilidad ${ }^{54}$. Se necesitan ensayos prospectivos, aleatorios y con mayor número de pacientes para poder valorar la utilidad diagnóstica del PSA: $\alpha_{2} \mathrm{M}$ en estos valores de PSA total.

\section{PSA: $\alpha_{1} A T$}

Zhang et al. ${ }^{64}$ desarrollaron un ensayo para medir el PSA unido al inhibidor de proteasa $\alpha_{1}$ AT. Los autores refieren, además, que hay diferencias en las concentraciones de esta forma molecular entre los pacientes con HBP y $\mathrm{CaP}$ con rangos de PSA total entre 4 y $20 \mathrm{ng} / \mathrm{ml}$, por lo que este marcador puede ser de utilidad en el diagnóstico de CaP.

\section{EMPLEO DE hK2 EN LA DETECCIÓN DEL CÁNCER DE PRÓSTATA}

La calicreína glandular humana 2 es expresada por el gen hKLK2 y antiguamente se la conocía como hGK1. Inicialmente no fue prácticamente tenida en cuenta por el enorme interés que produjo el PSA. Recientemente, la hK2 ha surgido como un potencial marcador tumoral debido a diversos descubrimientos intrigantes sobre el PSA y la hK2. Además de pertenecer a la misma familia de proteasas séricas, el PSA y la hK2 comparten numerosas propiedades. Las secuencias de aminoácidos del PSA y la hK2 son idénticas aproximadamente en el $80 \%{ }^{65}$. Ambas se expresan en el epitelio prostático y están presentes en el suero y el líquido seminal ${ }^{66-68}$. Sus expresiones están reguladas por los andrógenos ${ }^{69}$. En el suero, el PSA y la hK2 forman complejos con los inhibidores endógenos de la proteasa ${ }^{70}$.

En un principio se creyó que la hK2 sólo se expresaba en la próstata, pero se ha visto que también lo hace en otros lugares (mama, endometrio, glándulas salivales, etc. $)^{71,72}$.

La hK2 se encuentra en el plasma en diversas formas moleculares, al igual que el PSA. Parte de la hK2 está en forma libre, no acomplejada, de unos $32 \mathrm{kDa}$, que es la forma más frecuente en plasma o suero $^{73}$, mientras que otra parte se encuentra formando complejos con $\alpha_{1}$ ACT y $\alpha_{2}$ M. El complejo hK2: $\alpha_{1}$ ACT posee un peso molecular de $90 \mathrm{kDa}$. Los ensayos disponibles actualmente para la medida de 
la concentración de hK2 que emplean anticuerpos monoclonales detectan la hK2 libre y el complejo $\mathrm{hK2}: \alpha_{1} \mathrm{ACT}^{74}$. Aunque la hK2 forma fácilmente complejos con la $\alpha_{2} \mathrm{M}$ in vivo e in vitro igual que el PSA, los anticuerpos monoclonales disponibles actualmente no lo detectan en una cantidad significativa ${ }^{75}$.

La expresión de la hK2 está localizada en la próstata y es más específica del tumor que el PSA ${ }^{76}$. Así, a diferencia del PSA, la hK2 se expresa a niveles más altos en el tejido prostático poco diferenciado que en el bien diferenciado o benigno ${ }^{76,77}$. Además, la hK2 puede desempeñar un papel regulador del PSA porque la forma recombinante in vitro puede convertir al zimógeno del PSA inactivo (proPSA) en PSA enzimáticamente activo ${ }^{78,79}$. También se ha comprobado que la concentración del precursor de la hK2 (pro hK2) está aumentada en suero de pacientes con $\mathrm{CaP}$ y en el tejido prostático canceroso comparada con el tejido de la HBP o el tejido prostático normal ${ }^{80}$. A causa de estas propiedades particulares de la $\mathrm{hK} 2$, se han realizado recientemente esfuerzos centrados en la investigación de la posible utilidad de la hK2, por sí misma o junto con el PSA, en la detección del CaP.

Al igual que el PSA, la hK2 está presente en suero y plasma en diferentes formas moleculares ${ }^{81}$, bien libre o formando complejos con $\alpha_{1} \mathrm{ACT}, \alpha_{2} \mathrm{M}$ y C1-inactivador.

Los estudios clínicos iniciales identificaron la hK2 en el suero de aquellos pacientes con CaP que también tenían valores elevados de $\mathrm{PSA}^{82,83}$. La concentración de hK2 suele ser inferior al valor del PSA total en suero ${ }^{84-86}$. Así, en los hombres con PSA total entre 2 y $20 \mathrm{ng} / \mathrm{ml}$, los valores de la hK2 oscilan entre 0 y $350 \mathrm{pg} / \mathrm{ml}^{74}$. Algunos estudios han sugerido una correlación positiva entre la hK2 y el PSA total en suero ${ }^{73,85}$, mientras que otros no $^{67,74}$

Varios estudios han demostrado una mayor discriminación entre HBP y CaP al combinar la concentración de hK2 con la del PSA libre y total ${ }^{84,87-89}$ Algunos investigadores emplearon una prueba indirecta basada en la precipitación selectiva del PSA con anticuerpos específicos y posterior detección de la hK2, en el suero de los pacientes con valores de PSA total entre 4 y $10 \mathrm{ng} / \mathrm{ml}^{84,88}$. Sugirieron que la razón hK2/PSA libre puede discriminar mejor a los hombres con CaP cuando se compara con el PSA total o el porcentaje de PSA libre.
Nam et al. ${ }^{90}$ encontraron que el valor medio de la hK2 y la razón hK2/PSA libre eran significativamente superiores en los hombres con CaP en comparación con los que tenían cuadros prostáticos benignos. Un análisis de regresión logística multivariado demostró que la hK2 y la razón hK2/PSA libre, cuando se ajustaban según otras variables de predicción, incluyendo el PSA, contribuían de forma significativa e independiente a la detección del CaP y sugirió que la hK2 se puede usar de forma conjunta con el PSA.

Así, los ensayos clínicos sugieren que la hK2 puede usarse mejor junto con diversas formas de PSA para mejorar la utilidad del algoritmo actual de decisión. Sin embargo, no hay acuerdo sobre qué combinación variable es el mejor indicador diagnóstico y donde debe estar el valor límite. De esta forma, se necesitan estudios multicéntricos prospectivos para confirmar muchas observaciones hechas con estudios previos y para establecer exactamente el mejor predictor de CaP.

Existen muchas aplicaciones posibles de la hK2 en la detección de CaP en el futuro.

Primero, nuevos medios para cuantificar las diferentes formas de hK2 (en forma compleja o libre/no unida) contribuirán probablemente de forma independiente al tratamiento de CaP, como el $\mathrm{PSA}^{75}$

Segundo, la hK2 puede ser un objetivo ideal para la reacción en cadena de la polimerasa por transcripción inversa (RT-PCR) para detectar las células cancerosas circulantes que expresan el ARNm de la hK2. El entusiasmo inicial sobre la RT-PCR empleando el PSA como objetivo ha disminuido porque las células del CaP están poco diferenciadas y generalmente no expresan el PSA a valores elevados. Sin embargo, la RT-PCR que emplea la hK2 se puede realizar mejor, ya que el CaP en un estadio más avanzado parece expresar un valor más alto de hK2 $2^{91,92}$

Tercero, la radioinmunogammagrafía empleando la hK2 como objetivo puede ser útil porque la hK2 se expresa más en el CaP primario y en las metástasis en los ganglios linfáticos ${ }^{91}$.

Finalmente, se pueden desarrollar algoritmos multivariados y redes neurales artificiales empleando diferentes variables predictoras, incluyendo la hK2, para mejorar la detección actual del cáncer y la predicción del estadio ${ }^{93}$ 


\section{REFERENCIAS}

1. Martin BJ, Cheli CD, Sterling K, Ward M, Pollard S, Lifsey D, et al. Prostate specific antigen isoforms and human glandular kallikrein 2-which offers the best screening performance in a predominantly black population?. J Urol. 2006;175(1):104107.

2. Brawer MK. Screening for prostate cancer. Semin Surg Oncol. 2000; 18(1):29-36.

3. Hara M, Koyanagi Y, Inoue T, Fukuyama T. [Some physicochemical characteristics of "-seminoprotein", an antigenic component specific for human seminal plasma. Forensic immunological study of body fluids and secretion. VII]. Nippon Hoigaku Zasshi. 1971;25(4):322-324.

4. Seregni E, Botti C, Ballabio G, Bombardieri E. Biochemical characteristics and recent biological knowledge on prostatespecific antigen. Tumori. 1996;82(1):72-77.

5. Digby M, Zhang XY, Richards RI. Human prostate specific antigen (PSA) gene: structure and linkage to the kallikrein-like gene, hGK-1. Nucleic Acids Res. 1989;17(5):2137.

6. Cleutjens KB, van Eekelen CC, van der Korput HA, Brinkmann AO, Trapman J. Two androgen response regions cooperate in steroid hormone regulated activity of the prostate-specific antigen promoter. J Biol Chem. 1996;271(11):6379-88.

7. Henttu P, Liao SS, Vihko P. Androgens up-regulate the human prostate-specific antigen messenger ribonucleic acid (mRNA), but down-regulate the prostatic acid phosphatase mRNA in the LNCaP cell line. Endocrinology. 1992;130(2):766-772.

8. Shan JD, Porvari K, Ruokonen M, Karhu A, Launonen V, Hedberg P, et al. Steroid-involved transcriptional regulation of human genes encoding prostatic acid phosphatase, prostatespecific antigen, and prostate-specific glandular kallikrein. Endocrinology. 1997;138(9):3764-3770.

9. Wang MC, Papsidero LD, Kuriyama M, Valenzuela LA, Murphy GP, Chu TM. Prostate antigen: a new potential marker for prostatic cancer. Prostate. 1981;2(1):89-96.

10. Oesterling JE. Prostate specific antigen: a critical assessment of the most useful tumor marker for adenocarcinoma of the prostate. J Urol 1991;145(5):907-23.

11. Graves HC. Nonprostatic sources of prostate-specific antigen: a steroid hormone-dependent phenomenon?. Clin Chem. 1995;41(1):7-9.

12. Wang MC, Papsidero LD, Chu TM. Prostate-specific antigen, p30, gamma-seminoprotein, and E1. Prostate. 1994;24(2):107110.

13. Lilja H. A kallikrein-like serine protease in prostatic fluid cleaves the predominant seminal vesicle protein. J Clin Invest. 1985;76(5): 1899-1903.

14. Lilja H, Oldbring J, Rannevik G, Laurell CB. Seminal vesiclesecreted proteins and their reactions during gelation and liquefaction of human semen. J Clin Invest. 1987;80(2):281-285.

15. McGee RS, Herr JC. Human seminal vesicle-specific antigen is a substrate for prostate-specific antigen (or P-30). Biol Reprod. 1988;39(2):499-510.

16. Fortier AH, Nelson BJ, Grella DK, Holaday JW. Antiangiogenic activity of prostate-specific antigen. J Natl Cancer Inst. 1999; 91(19): 1635-1640.

17. Christensson A, Laurell CB, Lilja H. Enzymatic activity of prostate-specific antigen and its reactions with extracellular serine proteinase inhibitors. Eur J Biochem. 1990;194(3):755763.

18. Lilja H, Christensson A, Dahlen U, Matikainen MT, Nilsson O, Pettersson K, et al. Prostate-specific antigen in serum occurs predominantly in complex with alpha 1-antichymotrypsin. Clin Chem. 1991;37(9):1618-1625.
19. Stenman UH, Leinonen J, Alfthan H, Rannikko S, Tuhkanen K, Alfthan O. A complex between prostate-specific antigen and alpha 1-antichymotrypsin is the major form of prostate-specific antigen in serum of patients with prostatic cancer: assay of the complex improves clinical sensitivity for cancer. Cancer Res. 1991;51(1):222-226.

20. Vessella RL, Lange PH. Issues in the assessment of prostatespecific antigen immunoassays. An update. Urol Clin North Am. 1997;24(2):261-268.

21. McCormack RT, Rittenhouse HG, Finlay JA, Sokoloff RL, Wang $\mathrm{TJ}$, Wolfert RL, et al. Molecular forms of prostate-specific antigen and the human kallikrein gene family: a new era. Urology. 1995;45(5):729-744.

22. Mettlin CJ, Murphy GP, Ho R, Menck HR. The National Cancer Data Base report on longitudinal observations on prostate cancer. Cancer. 1996;77(10):2162-2166.

23. Benson MC, Whang IS, Pantuck A, Ring K, Kaplan SA, Olsson CA, et al. Prostate specific antigen density: a means of distinguishing benign prostatic hypertrophy and prostate cancer. $\mathrm{J}$ Urol. 1992;147(3 Pt 2):815-816.

24. Stamey TA, Yang N, Hay AR, McNeal JE, Freiha FS, Redwine E. Prostate-specific antigen as a serum marker for adenocarcinoma of the prostate. N Engl J Med. 1987;317(15):909-16.

25. Seaman E, Whang M, Olsson CA, Katz A, Cooner WH, Benson MC. PSA density (PSAD). Role in patient evaluation and management. Urol Clin North Am. 1993;20(4):653-663.

26. Catalona WJ, Richie JP, deKernion JB, Ahmann FR, Ratliff TL Dalkin BL, et al. Comparison of prostate specific antigen concentration versus prostate specific antigen density in the early detection of prostate cancer: receiver operating characteristic curves. J Urol. 1994;152(6 Pt 1):2031-2036.

27. Brawer MK, Aramburu EA, Chen GL, Preston SD, Ellis WJ. The inability of prostate specific antigen index to enhance the predictive the value of prostate specific antigen in the diagnosis of prostatic carcinoma. J Urol. 1993;150(2 Pt 1):369-373.

28. Djavan B, Marberger M, Zlotta A, Schulman CC. PSA, f/t-PSA, PSAD, PSA-TZ, and PSA-velocity for prostate cancer prediction: a multivariate analysis. J Urol. 1998;159:235.

29. Carter HB, Pearson JD, Metter EJ, Brant LJ, Chan DW, Andres $\mathrm{R}$, et al. Longitudinal evaluation of prostate-specific antigen levels in men with and without prostate disease. Jama. 1992; 267(16):2215-20

30. Oesterling JE, Cooner WH, Jacobsen SJ, Guess HA, Lieber MM. Influence of patient age on the serum PSA concentration. An important clinical observation. Urol Clin North Am. 1993;20(4):671-680.

31. DeAntoni EP, Crawford ED, Oesterling JE, Ross CA, Berger ER, McLeod DG, et al. Age and race-specific reference ranges for prostate-specific antigen from a large community-based study. Urology. 1996;48(2):234-239.

32. Lein M, Koenig F, Jung K, McGovern FJ, Skates SJ, Schnorr D, et al. The percentage of free prostate specific antigen is an ageindependent tumour marker for prostate cancer: establishment of reference ranges in a large population of healthy men. $\mathrm{Br} \mathrm{J}$ Urol. 1998;82(2):231-236.

33. Morgan TO, Jacobsen SJ, McCarthy WF, Jacobson DJ, McLeod DG, Moul JW. Age-specific reference ranges for prostate-specific antigen in black men. N Engl J Med. 1996; 335(5):304-310.

34. Oesterling JE, Jacobsen SJ, Klee GG, Pettersson K, Piironen T, Abrahamsson PA, et al. Free, complexed and total serum prostate specific antigen: the establishment of appropriate reference ranges for their concentrations and ratios. J Urol. 1995;154(3):1090-1095. 
35. Catalona WJ, Southwick PC, Slawin KM, Partin AW, Brawer MK, Flanigan RC, et al. Comparison of percent free PSA, PSA density, and age-specific PSA cutoffs for prostate cancer detection and staging. Urology. 2000;56(2):255-260.

36. Hofer C, Sauerstein P, Wolter C, Scholz M, Hartung R, Breul J. Value of free prostate-specific antigen (Hybritech Tandem-R) in symptomatic patients consulting the urologist. Urol Int. 2000;64(1): 18-23.

37. Lilja H. Structure, function, and regulation of the enzyme activity of prostate-specific antigen. World J Urol. 1993;11(4):188191.

38. Christensson A, Bjork T, Nilsson O, Dahlen U, Matikainen MT, Cockett AT, et al. Serum prostate specific antigen complexed to alpha 1-antichymotrypsin as an indicator of prostate cancer. J Urol. 1993;150(1):100-105.

39. Woodrum DL, Brawer MK, Partin AW, Catalona WJ, Southwick PC. Interpretation of free prostate specific antigen clinical research studies for the detection of prostate cancer. J Urol. 1998;159(1):5-12.

40. Okihara K, Ukimura O, Nakamura T, Mizutani Y, Kawauchi A, Naya Y, et al. Can complexed prostate specific antigen enhance prostate cancer detection in Japanese men?. Eur Urol. 2004;46(1):57-64

41. Kobayashi T, Kamoto T, Nishizawa K, Mitsumori K, Ogura K, Ide Y. Prostate-specific antigen (PSA) complexed to alpha1antichymotrypsin improves prostate cancer detection using total PSA in Japanese patients with total PSA levels of 2.0-4.0 ng/mL. BJU Int. 2005;95(6):761-765.

42. Okegawa T, Noda H, Nutahara K, Higashihara E. Comparisons of the various combinations of free, complexed, and total prostate-specific antigen for the detection of prostate cancer. Eur Urol. 2000;38(4):380-387

43. Saika T, Tsushima T, Nasu Y, Kusaka N, Miyaji Y, Takamoto H, et al. Prostate specific antigen complexed to alpha-1-antichymotrypsin in patients with intermediate prostate specific antigen levels. Cancer. 2002;94(6):1685-1691.

44. Jung K, Brux B, Lein M, Knabich A, Sinha P, Rudolph B, et al Determination of alphal-antichymotrypsin-PSA complex in serum does not improve the differentiation between benign prostatic hyperplasia and prostate cancer compared with total PSA and percent free PSA. Urology. 1999;53(6):1160-1167; discussion 1167-1168.

45. España F, Martinez M, Sanchez-Cuenca J, Vera CD, Estelles A, Jimenez-Cruz JF. Prostate-specific antigen and its complexes with alpha 1-antichymotrypsin in the plasma of patients with prostatic disease. Eur Urol. 1996;30(4):512-518.

46. Martínez M, España F, Royo M, Aznar J, Vera CD, Estellés A, et al. Formas moleculares del PSA: ¿qué aportan al diagnóstico del cáncer de próstata? Urol Integr Invest. 1998;3:173-177.

47. España F, Royo M, Martinez M, Enguidanos MJ, Vera CD, Estelles A, et al. Free and complexed prostate specific antigen in the differentiation of benign prostatic hyperplasia and prostate cancer: studies in serum and plasma samples. J Urol. 1998;160(6 Pt 1):2081-2088.

48. Martinez M, España F, Royo M, Vera CD, Estelles A, JimenezCruz JF, et al. Prostate-specific antigen complexed to alpha(1)antichymotrypsin in the early detection of prostate cancer. Eur Urol. 2000;38(1):85-90.

49. Martinez M, España F, Royo M, Alapont JM, Navarro S, Estelles A, et al. The proportion of prostate-specific antigen (PSA) complexed to alpha(1)-antichymotrypsin improves the discrimination between prostate cancer and benign prostatic hyperplasia in men with a total PSA of 10 to 30 microg/L. Clin Chem. 2002;48(8):1251-1256.
50. Brawer MK, Cheli CD, Neaman IE, Goldblatt J, Smith C, Schwartz MK, et al. Complexed prostate specific antigen provides significant enhancement of specificity compared with total prostate specific antigen for detecting prostate cancer. $\mathrm{J}$ Urol. 2000;163(5):1476-1480.

51. Partin AW, Brawer MK, Bartsch G, Horninger W, Taneja SS Lepor $\mathrm{H}$, et al. Complexed prostate specific antigen improves specificity for prostate cancer detection: results of a prospective multicenter clinical trial. J Urol. 2003;170(5):1787-1791.

52. Sokoll LJ, Bruzek DJ, Cox JL. Is complexed PSA alone clinically useful?. J Urol. 1998;159:895A.

53. Djavan B, Remzi M, Zlotta AR, Ravery V, Hammerer P, Reissigl A, et al. Complexed prostate-specific antigen, complexed prostate-specific antigen density of total and transition zone, complexed/total prostate-specific antigen ratio, free-to-total prostate-specific antigen ratio, density of total and transition zone prostate-specific antigen: results of the prospective multicenter European trial. Urology. 2002;60(4 Suppl 1):4-9.

54. Alapont Alacreu JM. Desarrollo y evaluación de nuevos marcadores diagnósticos y pronósticos en el cáncer de próstata [Tesis doctoral]. Valencia: Universidad de Valencia; 2007.

55. Okihara K, Cheli CD, Partin AW, Fritche HA, Chan DW, Sokoll $\mathrm{LJ}$, et al. Comparative analysis of complexed prostate specific antigen, free prostate specific antigen and their ratio in detecting prostate cancer. J Urol. 2002;167(5):2017-2023; discussion 2023-2024.

56. Stamey TA, Yemoto CE. Examination of the 3 molecular forms of serum prostate specific antigen for distinguishing negative from positive biopsy: relationship to transition zone volume. J Urol. 2000;163(1):119-126.

57. Parsons JK, Brawer MK, Cheli CD, Partin AW, Djavan R. Complexed prostate specific antigen (PSA) reduces unneces sary prostate biopsies in the $2.6-4.0 \mathrm{ng} / \mathrm{mL}$ range of total PSA. BJU Int. 2004;94(1):47-50.

58. Lein M, Kwiatkowski M, Semjonow A, Luboldt HJ, Hammerer $\mathrm{P}$, Stephan C, et al. A multicenter clinical trial on the use of complexed prostate specific antigen in low prostate specific antigen concentrations. J Urol. 2003;170(4 Pt 1):1175-1179.

59. Jung K, Stephan C, Elgeti U, Lein M, Brux B, Kristiansen G, et al. Molecular forms of prostate-specific antigen in serum with concentrations of total prostate-specific antigen $<4$ microg/L: are they useful tools for early detection and screening of prostate cancer?. Int J Cancer. 2001;93(5):759-765.

60. Okihara K, Fritsche HA, Ayala A, Johnston DA, Allard WJ, Babaian RJ. Can complexed prostate specific antigen and prostatic volume enhance prostate cancer detection in men with total prostate specific antigen between 2.5 and $4.0 \mathrm{ng} . / \mathrm{ml}$. J Urol. 2001;165(6 Pt 1):1930-1936.

61. España F, Sanchez-Cuenca J, Estelles A, Gilabert J, Griffin JH, Heeb MJ. Quantitative immunoassay for complexes of prostate-specific antigen with alpha2-macroglobulin. Clin Chem. 1996;42(4):545-550.

62. Zhang WM, Finne P, Leinonen J, Vesalainen S, Nordling S, Rannikko S, et al. Characterization and immunological determination of the complex between prostate-specific antigen and alpha2-macroglobulin. Clin Chem. 1998;44(12):2471-2479.

63. Zhang WM, Finne P, Leinonen J, Salo J, Stenman UH. Determination of prostate-specific antigen complexed to alpha(2)-macroglobulin in serum increases the specificity of free to total PSA for prostate cancer. Urology. 2000;56(2):267-272.

64. Zhang WM, Finne P, Leinonen J, Vesalainen S, Nordling S, Stenman UH. Measurement of the complex between prostatespecific antigen and alphal-protease inhibitor in serum. Clin Chem. 1999;45(6 Pt 1):814-821. 
65. Young CY, Andrews PE, Montgomery BT, Tindall DJ. Tissuespecific and hormonal regulation of human prostate-specific glandular kallikrein. Biochemistry. 1992;31(3):818-824.

66. Deperthes D, Chapdelaine P, Tremblay RR, Brunet C, Berton J, Hebert $\mathrm{J}$, et al. Isolation of prostatic kallikrein hK2, also known as hGK-1, in human seminal plasma. Biochim Biophys Acta. 1995;1245(3):311-316.

67. Finlay JA, Evans CL, Day JR, Payne JK, Mikolajczyk SD, Millar LS, et al. Development of monoclonal antibodies specific for human glandular kallikrein (hK2): development of a dual antibody immunoassay for hK2 with negligible prostate-specific antigen cross-reactivity. Urology. 1998;51(5):804-809.

68. Wang TJ, Rittenhouse HG, Wolfert RL, Lynne CM, Brackett NL. PSA concentrations in seminal plasma. Clin Chem. 1998;44(4): 895-896.

69. Murtha P, Tindall DJ, Young CY. Androgen induction of a human prostate-specific kallikrein, hKLK2: characterization of an androgen response element in the 5' promoter region of the gene. Biochemistry. 1993;32(25):6459-6464.

70. Mikolajczyk SD, Millar LS, Kumar A, Saedi MS. Human glandular kallikrein, hK2, shows arginine-restricted specificity and forms complexes with plasma protease inhibitors. Prostate. 1998;34(1):44-50.

71. Chapdelaine P, Paradis G, Tremblay RR, Dube JY. High level of expression in the prostate of a human glandular kallikrein mRNA related to prostate-specific antigen. FEBS Lett. 1988; 236(1):205-208.

72. Morris BJ. hGK-1: a kallikrein gene expressed in human prostate. Clin Exp Pharmacol Physiol. 1989;16(4):345-351.

73. Black MH, Magklara A, Obiezu CV, Melegos DN, Diamandis EP. Development of an ultrasensitive immunoassay for human glandular kallikrein with no cross-reactivity from prostate-specific antigen. Clin Chem. 1999;45(6 Pt 1):790-799.

74. Partin AW, Catalona WJ, Finlay JA, Darte C, Tindall DJ, Young $\mathrm{CY}$, et al. Use of human glandular kallikrein 2 for the detection of prostate cancer: preliminary analysis. Urology. 1999;54(5): 839-845.

75. Grauer LS, Finlay JA, Mikolajczyk SD, Pusateri KD, Wolfert RL. Detection of human glandular kallikrein, hK2, as its precursor form and in complex with protease inhibitors in prostate carcinoma serum. J Androl. 1998;19(4):407-411.

76. Darson MF, Pacelli A, Roche P, Rittenhouse HG, Wolfert RL Young CY, et al. Human glandular kallikrein 2 (hK2) expression in prostatic intraepithelial neoplasia and adenocarcinoma: a novel prostate cancer marker. Urology. 1997;49(6):857-862.

77. Tremblay RR, Deperthes D, Tetu B, Dube JY. Immunohistochemical study suggesting a complementary role of kallikreins hK2 and hK3 (prostate-specific antigen) in the functional analysis of human prostate tumors. Am J Pathol. 1997;150(2): 455-459.

78. Kumar A, Mikolajczyk SD, Goel AS, Millar LS, Saedi MS Expression of pro form of prostate-specific antigen by mammalian cells and its conversion to mature, active form by human kallikrein 2. Cancer Res. 1997;57(15):3111-3114.

79. Takayama TK, Fujikawa K, Davie EW. Characterization of the precursor of prostate-specific antigen. Activation by trypsin and by human glandular kallikrein. J Biol Chem. 1997;272 (34):21582-21588.

80. Saedi MS, Hill TM, Kuus-Reichel K, Kumar A, Payne J, Mikolajczyk SD, et al. The precursor form of the human kallikrein 2, a kallikrein homologous to prostate-specific antigen, is present in human sera and is increased in prostate cancer and benign prostatic hyperplasia. Clin Chem. 1998;44(10): 2115-2119.
81. Heeb MJ, España F. Alpha2-macroglobulin and C1-inactivator are plasma inhibitors of human glandular kallikrein. Blood Cells Mol Dis. 1998;24(4):412-419.

82. Charlesworth MC, Young CY, Klee GG, Saedi MS, Mikolajczyk SD, Finlay JA, et al. Detection of a prostate-specific protein, human glandular kallikrein (hK2), in sera of patients with elevated prostate-specific antigen levels. Urology. 1997;49(3):487493

83. Rittenhouse HG, Tindall DJ, Klee GG. Characterization and evaluation of hK2; A potential prostate cancer marker, closely related to PSA. Proceedings of the First International Consultation on Prostate Cancer. 1996.

84. Kwiatkowski MK, Recker F, Piironen T, Pettersson K, Otto T, Wernli $\mathrm{M}$, et al. In prostatism patients the ratio of human glandular kallikrein to free PSA improves the discrimination between prostate cancer and benign hyperplasia within the diagnostic "gray zone" of total PSA 4 to $10 \mathrm{ng} / \mathrm{mL}$. Urology. 1998;52(3):360-365

85. Piironen T, Lovgren J, Karp M, Eerola R, Lundwall A, Dowell B, et al. Immunofluorometric assay for sensitive and specific measurement of human prostatic glandular kallikrein (hK2) in serum. Clin Chem. 1996;42(7):1034-1041.

86. Becker C, Piironen T, Pettersson K, Bjork T, Wojno KJ, Oesterling JE, et al. Discrimination of men with prostate cancer from those with benign disease by measurements of human glandular kallikrein 2 (HK2) in serum. J Urol. 2000;163(1):311316 .

87. Magklara A, Scorilas A, Catalona WJ, Diamandis EP. The combination of human glandular kallikrein and free prostate-specific antigen (PSA) enhances discrimination between prostate cancer and benign prostatic hyperplasia in patients with moderately increased total PSA. Clin Chem. 1999;45(11):1960-1966.

88. Recker F, Kwiatkowski MK, Piironen T, Pettersson K, Lummen G, Wernli M, et al. The importance of human glandular kallikrein and its correlation with different prostate specific antigen serum forms in the detection of prostate carcinoma. Cancer. 1998;83(12):2540-2547.

89. Becker C, Piironen T, Pettersson K, Hugosson J, Lilja H. Clinical value of human glandular kallikrein 2 and free and total prostate-specific antigen in serum from a population of men with prostate-specific antigen levels $3.0 \mathrm{ng} / \mathrm{mL}$ or greater. Urology. 2000;55(5):694-699.

90. Nam RK, Diamandis EP, Toi A, Trachtenberg J, Magklara A, Scorilas A, et al. Serum human glandular kallikrein-2 protease levels predict the presence of prostate cancer among men with elevated prostate-specific antigen. J Clin Oncol. 2000;18(5): 10361042

91. Darson MF, Pacelli A, Roche P, Rittenhouse HG, Wolfert RL, Saeid MS, et al. Human glandular kallikrein 2 expression in prostate adenocarcinoma and lymph node metastases. Urology. 1999;53(5):939-944.

92. Corey E, Arfman EW, Oswin MM, Melchior SW, Tindall DJ, Young CY, et al. Detection of circulating prostate cells by reverse transcriptase-polymerase chain reaction of human glandular kallikrein (hK2) and prostate-specific antigen (PSA) messages. Urology. 1997;50(2):184-188.

93. Stephan C, Jung K, Soosaipillai A, Yousef GM, Cammann H, Meyer H, et al. Clinical utility of human glandular kallikrein 2 within a neural network for prostate cancer detection. BJU Int. 2005;96(4):521-527.

94. Catalona WJ, Smith DS, Wolfert RL, Wang TJ, Rittenhouse HG, Ratliff TL, et al. Evaluation of percentage of free serum prostate-specific antigen to improve specificity of prostate cancer screening. Jama. 1995;274(15):1214-1220. 
95. Morote J, Raventos CX, Lorente JA, Lopez-Pacios MA, Encabo $\mathrm{G}$, de Torres I, et al. Comparison of percent free prostate specific antigen and prostate specific antigen density as methods to enhance prostate specific antigen specificity in early prostate cancer detection in men with normal rectal examination and prostate specific antigen between 4.1 and $10 \mathrm{ng} . / \mathrm{ml}$. J Urol. 1997; 158(2):502-504.

96. Bangma CH, Rietbergen JB, Kranse R, Blijenberg BG, Petterson K, Schroder FH. The free-to-total prostate specific antigen ratio improves the specificity of prostate specific antigen in screening for prostate cancer in the general population. J Urol. 1997;157(6):2191-2196.

97. Brawer MK, Meyer GE, Letran JL, Bankson DD, Morris DL, Yeung KK, et al. Measurement of complexed PSA improves specificity for early detection of prostate cancer. Urology. 1998;52(3):372-378.

98. Kuriyama M, Kawada Y, Arai Y, Maeda H, Egawa S, Koshiba K et al. Significance of free to total PSA ratio in men with slightly elevated serum PSA levels: a cooperative study. Jpn J Clin Oncol. 1998;28(11):661-665.

99. Partin AW, Brawer MK, Subong EN, Kelley CA, Cox JL, Bruzek DJ, et al. Prospective evaluation of percent free-PSA and complexed-PSA for early detection of prostate cancer. Prostate Cancer Prostatic Dis. 1998;1(4):197-203.

100. Martinez-Pineiro L, Tabernero A, Contreras T, Madero R, Lozano D, Lopez-Tello J, et al. Determination of the percentage of free prostate-specific antigen helps to avoid unnecessary biopsies in men with normal rectal examinations and total prostate-specific antigen of 4-10 ng/ml. Eur Urol. 2000; 37(3):289-296.

101. Vessella RL, Lange PH, Partin AW, Chan DW, Sokoll LJ, Sasse EA, et al. Probability of prostate cancer detection based on results of a multicenter study using the AxSYM free PSA and total PSA assays. Urology. 2000;55(6):909-914.

102. Haese A, Dworschack RT, Partin AW. Percent free prostate specific antigen in the total prostate specific antigen 2 to 4 $\mathrm{ng} . / \mathrm{ml}$. range does not substantially increase the number of biopsies needed to detect clinically significant prostate cancer compared to the 4 to $10 \mathrm{ng} . / \mathrm{ml}$. range. J Urol. 2002;168(2): 504-508.

103. Catalona WJ, Smith DS, Ornstein DK. Prostate cancer detection in men with serum PSA concentrations of 2.6 to 4.0 $\mathrm{ng} / \mathrm{mL}$ and benign prostate examination. Enhancement of specificity with free PSA measurements. Jama. 1997;277(18): 1452-1455.

104. Prestigiacomo AF, Stamey TA. Can free and total prostate specific antigen and prostatic volume distinguish between men with negative and positive systematic ultrasound guided prostate biopsies?. J Urol. 1997;157(1):189-194.

105. Catalona WJ, Partin AW, Finlay JA, Chan DW, Rittenhouse $\mathrm{HG}$, Wolfert RL, et al. Use of percentage of free prostate-specific antigen to identify men at high risk of prostate cancer when PSA levels are 2.51 to $4 \mathrm{ng} / \mathrm{mL}$ and digital rectal examination is not suspicious for prostate cancer: an alternative model. Urology. 1999;54(2):220-224.

106. Djavan B, Zlotta A, Kratzik C, Remzi M, Seitz C, Schulman $\mathrm{CC}$, et al. PSA, PSA density, PSA density of transition zone, free/total PSA ratio, and PSA velocity for early detection of prostate cancer in men with serum PSA 2.5 to $4.0 \mathrm{ng} / \mathrm{mL}$. Urology. 1999;54(3):517-522.

107. Roehl KA, Antenor JA, Catalona WJ. Robustness of free prostate specific antigen measurements to reduce unnecessary biopsies in the 2.6 to $4.0 \mathrm{ng} . / \mathrm{ml}$. range. J Urol. 2002 168(3):922-925.

108. Horninger W, Cheli CD, Babaian RJ, Fritsche HA, Lepor H Taneja SS, et al. Complexed prostate-specific antigen for early detection of prostate cancer in men with serum prostate-specific antigen levels of 2 to 4 nanograms per milliliter. Urology. 2002;60(4 Suppl 1):31-35.

109. Maeda H, Arai Y, Aoki Y, Okubo K, Okada T, Maekawa S. Complexed prostate-specific antigen and its volume indexes in the detection of prostate cancer. Urology. 1999;54(2):225-228.

110. Okegawa T, Noda H, Nutahara K, Higashihara E. Comparison of two investigative assays for the complexed prostate-specific antigen in total prostate-specific antigen between 4.1 and $10.0 \mathrm{ng} / \mathrm{mL}$. Urology. 2000;55(5):700-704.

Correspondencia autor: Dr. JM Alapont Alacreu Servicio de Urología. Hospital Universitario La Fe. Avda. Campanar, 21- 46009 Valencia. Tel.: 963862700 E-mail autor: jmalapont@mundofree.com Información artículo: Original - Cáncer de próstata Trabajo recibido: marzo 2008

Trabajo aceptado: abril 2008 